\title{
Facile and Reproducible Synthesis of Nanostructured Colloidal ZnO Nanoparticles from Zinc Acetylacetonate: Effect of Experimental Parameters and Mechanistic Investigations
}

\author{
Alessia Famengo, ${ }^{[a]}$ Sankaran Anantharaman, ${ }^{[b]}$ Gloria Ischia, ${ }^{[c]}$ Valerio Causin, ${ }^{[a]}$ \\ Marta Maria Natile, ${ }^{[a]}$ Chiara Maccato, ${ }^{[a]}$ Eugenio Tondello, ${ }^{[a]}$ Helmut Bertagnolli, ${ }^{[b]}$ and \\ Silvia Gross $*[a]$
}

Keywords: Zinc oxide / Nanostructures / Colloids / Hydrolysis

\begin{abstract}
A facile and reproducible route to nanostructured colloidal $\mathrm{ZnO}$ nanoparticles was developed by controlled hydrolysis and condensation of zinc acetylacetonate in alkaline conditions. By reaction of an ethanolic solution of $\mathrm{Zn}(\mathrm{acac})_{2}$ with $\mathrm{NaOH}$ in a 1:2 molar ratio, after reflux, $\mathrm{ZnO}$ spherical nanoparticles were obtained that displayed a homogeneous size distribution; particle diameters ranged from 6 to $10 \mathrm{~nm}$, as evidenced by transmission electron microscopy (TEM) analysis. The same reaction was carried out also in water, glycerol and 1,2-propanediol, to investigate the effect of the solvent viscosity and dielectric constant on the final features of the obtained material. Irrespective of the nature of the solvent, $\mathrm{X}$-ray diffraction (XRD) analysis shows the formation of hexagonal $\mathrm{ZnO}$, whereas the presence of residual unreacted $\mathrm{Zn}(\mathrm{acac})_{2}$ could be ruled out. Indeed, different particle sizes and very different morphologies were obtained. Also the reflux step was shown to be a key factor in avoiding the fast precipitation of a floc and achieving a pure compound, which
\end{abstract}

was isolated and thoroughly characterised. The composition of the obtained $\mathrm{ZnO}$ was determined by elemental analysis, $\mathrm{X}$-ray photoelectron spectroscopy (XPS) and thermogravimetric analysis (TGA), showing the formation of pure $\mathrm{ZnO}$. IR spectroscopy evidenced the presence of adsorbed organic ligands on the colloid surfaces. Diffuse reflectance infrared Fourier transform spectroscopy (DRIFT) revealed the presence of medium- to high-strength acidic sites on the $\mathrm{ZnO}$ surface. To gain a deeper insight into the formation mechanisms of these nanostructures, time-resolved UV/Vis and XAS studies were performed on the ethanol solution used for the synthesis of the oxide and also on the solid specimen, obtained after the refluxing step. No remarkable changes could be evidenced in the solution after the addition of an understoichiometric amount of $\mathrm{NaOH}$, but the growth of the $\mathrm{ZnO}$ nanoparticles could be followed by UV/Vis spectra.

(@ Wiley-VCH Verlag GmbH \& Co. KGaA, 69451 Weinheim, Germany, 2009)

\section{Introduction}

Research in the field of $\mathrm{ZnO}$ nanostructures of different shapes and morphologies has witnessed an amazing development in the last 10 years. $^{[1]}$ This interest can be mainly traced back to the electrical and optical properties of $\mathrm{ZnO}^{[2]}$ as well as to its outstanding electronic properties and functional performances, ${ }^{[3]}$ which are in many cases related to defectivity. ${ }^{[4]}$ Also its photocatalytic properties have been recently extensively reviewed. ${ }^{[5]}$ Among the very different morphologies that $\mathrm{ZnO}$ can display (nanowires, nanotubes,

[a] Istituto di Scienze e Tecnologie Molecolari, ISTM-CNR and Dipartimento di Scienze Chimiche, Università degli Studi di Padova, and INSTM, UdR Padova,

Via Marzolo 1, 35131 Padova, Italy

E-mail: silvia.gross@unipd.it

[b] Institut für Physikalische Chemie, Universität Stuttgart, Pfaffenwaldring 55, 70569 Stuttgart, Germany

[c] Dipartimento di Ingegneria dei Materiali e Tecnologie Industriali, Università di Trento,

Via Mesiano 77, 38100 Trento, Italy

Supporting information for this article is available on the WWW under http://dx.doi.org/10.1002/ejic.200900506. nanoparticles, nanoplatelets, nanowhiskers, etc. $),{ }^{[6]}$ colloidal nanosized particles are particularly appealing for their functional properties and also because the spherical shape enhances the contribution of the intrinsic properties of $\mathrm{ZnO}$ with respect to that provided by the presence of defects. These suspensions can be approached by classical methods of colloid chemistry ${ }^{[7]}$ as well as by solvo- and hydrothermal methods. ${ }^{[8]}$ Different synthesis approaches to $\mathrm{ZnO}$ colloids have been reviewed by Spanhel. ${ }^{[9]}$ Recently, Niederberger, Pinna et al. have developed an effective and easy nonaqueous route to prepare crystalline metal oxide nanoparticles, including $\mathrm{ZnO}$ ones. ${ }^{[10]}$

The outstanding functional properties of $\mathrm{ZnO}$ nanoparticles push the research towards the development of new, easy, low-cost and reproducible preparative routes, yielding pure nanostructured $\mathrm{ZnO}$ colloids. ${ }^{[1]}$

In the present work, we address the synthesis of $\mathrm{ZnO}$ by using a wet-synthesis route based on the use of zinc acetylacetonate as precursor and four different solvents as dispersing media. Zinc acetylacetonate has been extensively used as a volatile precursor for the vapour and MOCVD 
deposition of $\mathrm{ZnO}^{[11]} \mathrm{ZnO}$ could also be obtained, starting with zinc acetylacetonate, by pyrolysis processes, ${ }^{[12]}$ chemical spray deposition, ${ }^{[13]}$ laser-induced deposition ${ }^{[14]}$ or epitaxial growth. ${ }^{[15]}$ Liu et al. have produced $\mathrm{ZnO}$ nanoparticles by degradation of a zinc acetylacetonate precursor in oleylamine, ${ }^{[16]}$ whereas Chory et al. have grown $\mathrm{ZnO}$ nanoparticles from ethanol solutions using acetate, acetylacetonate and dimethylpropylenediamine as stabiliser agents. ${ }^{[17]}$ Acetylacetonate has been used as a precursor also by Epifani, Iwasaki et al. ${ }^{[18,19]}$

However, to the best of our knowledge, this is the first study devoted to the synthesis of $\mathrm{ZnO}$ in these particular conditions and using different dispersing media. In this framework, the main goal of the present work was to develop a facile, reproducible, cost-effective, low-temperature and fast synthesis route for the production of monodispersed $\mathrm{ZnO}$ colloidal suspension. A related purpose was to investigate the effect of the chemicophysical nature of the dispersing medium on the formation and the evolution of the colloidal suspension. To this aim, time-resolved UV/Vis and EXAFS studies were also carried out.

\section{Results and Discussion}

\section{Time-Resolved Studies on the Nucleation and Growth of ZnO Nanoparticles}

Firstly, an attempt to follow the nucleation and growth of $\mathrm{ZnO}$ nanoparticles was carried out by time-resolved UV/ Vis and EXAFS measurements. Zinc acetylacetonate is a stable chelate complex, which, upon reaction with $\mathrm{NaOH}$ in ethanol under reflux, yields $\mathrm{ZnO}$ nanoparticles. The controlled particle growth during nucleation is essential in order to produce nanoparticles of reasonable size distribution. From the literature, ${ }^{[20]}$ the reaction steps that occur when $\mathrm{Zn}(\mathrm{acac})_{2}$ reacts with an ethanol solution of $\mathrm{NaOH}$ are
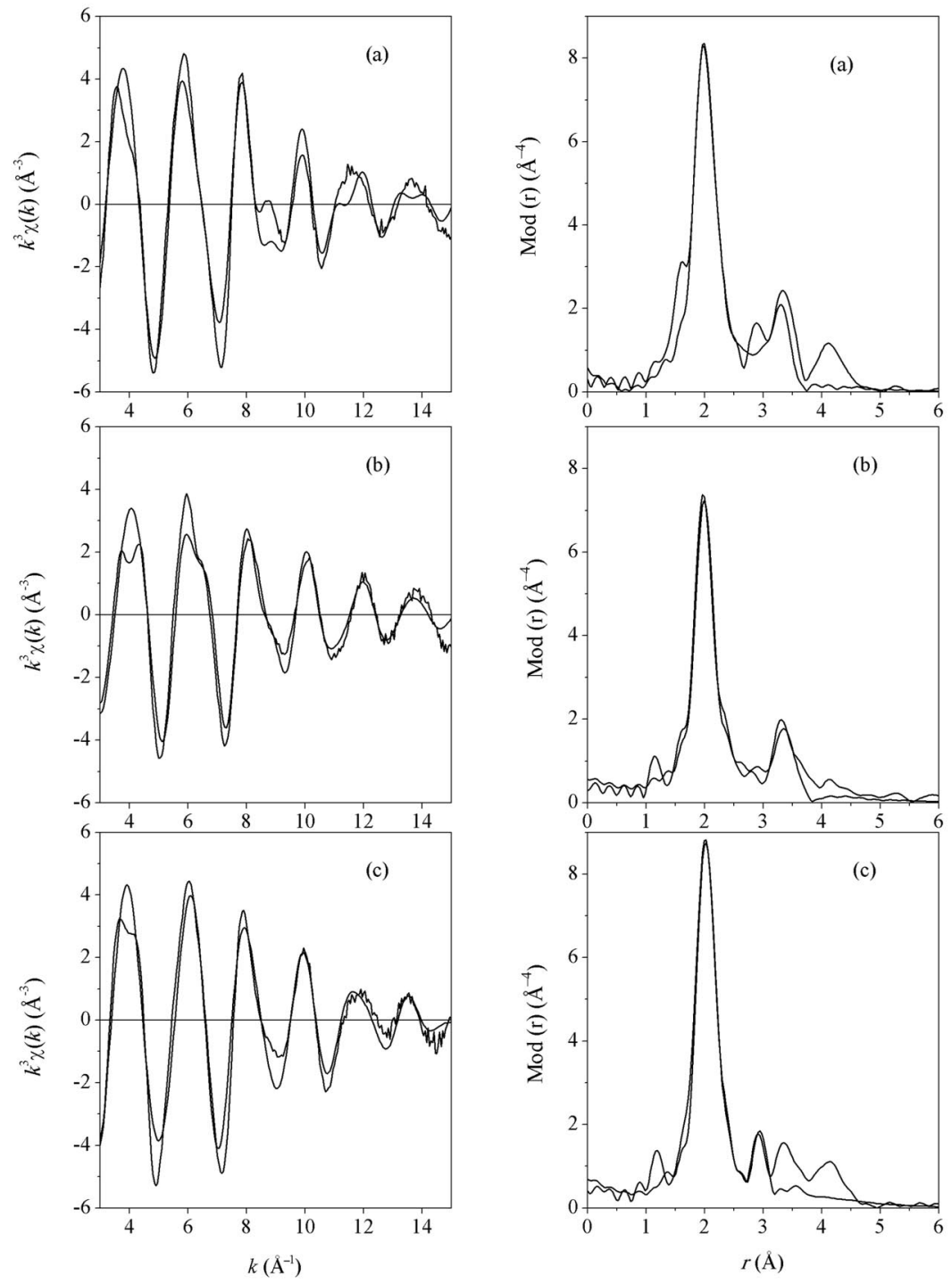

Figure 1. The $k^{3}$-weighted EXAFS function (left) and its Fourier transform (right) along with the theoretical models used in the fit of (a) solid anhydrous $\mathrm{Zn}(\mathrm{acac})_{2}$ reference (1a), (b) solution intermediate with $\mathrm{Zn}(\mathrm{OAc})_{2}$ treated with $\mathrm{NaOH}$ in ethanol (1b) and (c) $\mathrm{Zn}(\mathrm{acac})_{2}$ in EtOH after addition of $\mathrm{NaOH}(1 \mathrm{c})$. 
known to be the decomposition of $\mathrm{acac}^{-}$ligand and the subsequent formation of $\mathrm{Zn}-\mathrm{O}-\mathrm{Zn}$ bonded species during the reflux step. Moreover, few investigations have been carried out on the various equilibria between the zinc complexes in solution. Consequently, the identification of the main species that undergoes hydrolysis has been performed by EXAFS measurements. The present EXAFS investigation aims to confirm the presence of such $\mathrm{Zn}-\mathrm{O}-\mathrm{Zn}$-type intermediates using the local structure of zinc, obtained from EXAFS data analysis. The experimental $k^{3}$-weighted EXAFS spectra of solid anhydrous $\mathrm{Zn}(\mathrm{acac})_{2}$ (1a), $\mathrm{Zn}(\mathrm{acac})_{2}$ dissolved in $\mathrm{EtOH}$ and treated with $\mathrm{NaOH}(\mathbf{1 c})$, and $\mathrm{Zn}(\mathrm{OAc})_{2}$ dissolved in $\mathrm{EtOH}$ and treated with $\mathrm{NaOH}$ (1b) are presented in Figure 1 along with their Fouriertransformed EXAFS spectra.

From the comparison of the $k^{3}$-weighted EXAFS spectra, the oscillations in $k$-space and the Fourier transform peaks for samples $\mathbf{1 b}$ and $\mathbf{1 c}$ look different. On the other hand, 1b looks similar to 1a, that is anhydrous $\mathrm{Zn}(\mathrm{acac})_{2}$, which is trimeric (see Figure 2).

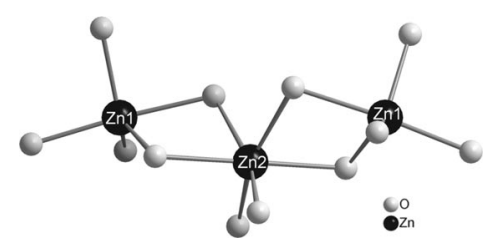

Figure 2. Molecular structure of trimeric zinc acetylacetonate used in the EXAFS modelling.

This observation gives an indication that the solution intermediate obtained from $\mathrm{Zn}(\mathrm{acac})_{2}$ is different from that obtained by starting from $\mathrm{Zn}(\mathrm{OAc})_{2}$. However, compared to solid anhydrous $\mathrm{Zn}(\mathrm{acac})_{2}$, the spectra of the liquid solution (1c) show a slight increase in intensity of the peak at around $1.9 \AA$ and a decrease in intensity of the peak at around $3.2 \AA$. In order to gain accurate insight into the type of the reaction species in solution, the structure of the starting solid material has to be known precisely. The experimental EXAFS spectra of the anhydrous $\mathrm{Zn}(\mathrm{acac})_{2}$ were fitted with theoretical EXAFS phase and amplitude functions calculated using FEFF6 for the crystal structure of anhydrous $\mathrm{Zn}(\mathrm{acac})_{2} .^{[21]}$ The fit to the experimental data in $R$-space (Fourier transformed EXAFS) using the theoretically calculated FEFF paths of trimeric $\mathrm{Zn}(\mathrm{acac})_{2}$ as a twosite model was performed by the iteration of the change in half path length $\Delta R$, Debye-Waller-like factor $\sigma^{2}$ and energy shift $E_{0}$ for each path, with fixed values for path degeneracy. In the fitting model, the distorted octahedral arrangement of oxygen around the $\mathrm{Zn} 2$ site and a distorted trigonal bipyramidal coordination of five oxygen atoms around $\mathrm{Zn} 1$ were considered (see Figure 2). The $\mathrm{Zn}-\mathrm{Zn}$ distances were constrained for both $\mathrm{Zn} 1$ and $\mathrm{Zn} 2$ (see Exp. Section) centres to be equal. Within the error limits, the obtained fits were statistically satisfactory and the resulting model structure, presented in Table 1, was used as a yard stick to evaluate the changes that might be evidenced in the zinc species present in ethanol solution. When the experimental
EXAFS spectrum of $\mathbf{1 c}$ was compared with the solid reference 1a, no considerable changes were observed in the position of the FT peaks. The monitoring of the reaction of an ethanol solution of $\mathrm{Zn}(\mathrm{acac})_{2}$ with $\mathrm{NaOH}$ and the possible reaction mechanism involving different intermediates has been reported earlier in the literature. ${ }^{[20]}$ In the above-mentioned study, gas liquid chromatography (GLC) and highpressure liquid chromatography (HPLC) were used to monitor the products of $\mathrm{C}-\mathrm{C}$ bond cleavage in the ligands and as an inference the local structure around zinc was postulated in the mechanism. In this work, a direct probe of the local structure at the Zn K-edge using EXAFS was used to obtain the local structure around zinc. A strong FT peak at about $1.9 \AA$ and less intense peaks at 2.7 and $3.2 \AA$ are seen in the FT EXAFS spectra of 1c, similar to the $\mathrm{Zn}$ $(\text { acac })_{2}$ reference. However when this model was used in the fitting, it resulted in a statistically poorer fit. Similarly poor fits were obtained when the models consisting of either $\mathrm{Zn}_{4} \mathrm{O}\left(\mathrm{CH}_{3} \mathrm{COO}\right)_{6}$ or $\mathrm{Zn}(\mathrm{OH})_{2}$ were used. However, the model consisting of four $\mathrm{Zn}-\mathrm{O}$ neighbours and two $\mathrm{Zn}-\mathrm{C}$ neighbours resulted in a statistically good fit. The model and the fitting parameters obtained as results are presented in Table 1. Therefore, from the EXAFS investigations, no specific structure could be assigned to the intermediate formed in solution and only the immediate local environment around zinc could be ascertained. This is due to the fact that at a given time, during dissolution of the stable chelate complex, or during $\mathrm{NaOH}$ addition, different species coexist in solution and what is obtained as an EXAFS spectrum is actually an average of different local structure contributions. This limitation of EXAFS is well known. Also, neither a polymeric nor cluster model structure of $\mathrm{Zn}_{4} \mathrm{O}\left(\mathrm{COOCH}_{3}\right)_{6}$ species reported while using zinc acetate precursor for $\mathrm{ZnO}$ synthesis could be evidenced by the EXAFS fitting procedure because the inclusion of higher $\mathrm{Zn}-\mathrm{Zn}$ coordination paths resulted in poorer fits. In summary, it can be concluded that the local structure around zinc is not found to change dramatically upon dissolution in EtOH. Also, upon subsequent reflux no significant changes were observed. When $\mathrm{NaOH}$ was added in a stoichiometric ratio, the following observations were made: the immediate $\mathrm{Zn}-\mathrm{O}$ and $\mathrm{Zn}-\mathrm{C}$ coordination remain almost intact; and $\mathrm{Zn}-\mathrm{Zn}$ coordination similar to that found in the intermediate obtained with zinc acetate precursor could not be detected in solution even after $\mathrm{NaOH}$ addition.

In Figure 3, the UV/Vis spectra of the suspension collected at different time intervals $(0,50,80,110,230,260$, 290 min) after the addition of $\mathrm{NaOH}$ at a molar ratio of $\mathrm{OH}^{-} / \mathrm{Zn}^{2+}$ equal to 0.016 at $80{ }^{\circ} \mathrm{C}$ are plotted. As can be seen in Figure 3, formation of $\mathrm{ZnO}$ starts 110 min after the addition of $\mathrm{NaOH}$. A shift at higher wavelength with increasing time is observed, which can be traced back to the growth of the nanoparticles. Nanoparticles having a diameter of $4 \mathrm{~nm}$ were detected at $260 \mathrm{~min}$, whereas at $290 \mathrm{~min}$ they had grown to $7 \mathrm{~nm}$. These values are slightly higher than those detected by TEM and XRD (vide infra), being in the range $6-10 \mathrm{~nm}$, but still in the range of the standard deviation. 
Table 1. The parameters obtained from the fitting procedure for different paths for the samples $\mathbf{1 a}, \mathbf{1 b}$ and $\mathbf{1 c}$.

\begin{tabular}{|c|c|c|c|c|c|c|c|c|}
\hline Sample & Path & Degeneracy $^{[\mathrm{a}]}$ & Amplitude ${ }^{[\mathrm{a}]}$ & $\sigma^{2}\left(\AA^{2}\right)$ & $E_{0}(\mathrm{eV})$ & $R_{\text {eff }}(\AA)$ & $\Delta R(\AA)$ & $R(\AA)$ \\
\hline \multirow[t]{6}{*}{ 1a site 1} & $\mathrm{Zn} 1 \leftrightarrow \mathrm{O}$ & 1.0 & 0.67 & 0.0054 & -0.189 & 1.971 & -0.023 & 1.948 \\
\hline & $\mathrm{Zn} 1 \leftrightarrow \mathrm{O}$ & 1.0 & 0.67 & 0.0054 & -0.189 & 2.002 & -0.005 & 1.997 \\
\hline & $\mathrm{Zn} 1 \leftrightarrow \mathrm{O}$ & 1.0 & 0.67 & 0.0054 & -0.189 & 2.008 & -0.010 & 1.998 \\
\hline & $\mathrm{Zn} 1 \leftrightarrow \mathrm{O}$ & 1.0 & 0.67 & 0.0038 & -0.189 & 2.054 & 0.026 & 2.081 \\
\hline & $\mathrm{Zn} 1 \leftrightarrow \mathrm{O}$ & 1.0 & 0.67 & 0.0038 & -0.189 & 2.096 & 0.035 & 2.131 \\
\hline & $\mathrm{Zn} 1 \leftrightarrow \mathrm{Zn} 2$ & 1.0 & 0.67 & 0.0074 & -0.189 & 3.259 & -0.023 & 3.236 \\
\hline \multirow[t]{4}{*}{ 1a site 2} & $\mathrm{Zn} 2 \leftrightarrow \mathrm{O}$ & 2.0 & 0.33 & 0.0030 & -0.189 & 2.014 & -0.045 & 1.969 \\
\hline & $\mathrm{Zn} 2 \leftrightarrow \mathrm{O}$ & 2.0 & 0.33 & 0.0038 & -0.189 & 2.108 & -0.123 & 1.985 \\
\hline & $\mathrm{Zn} 2 \leftrightarrow \mathrm{O}$ & 2.0 & 0.33 & 0.0038 & -0.189 & 2.167 & -0.106 & 2.060 \\
\hline & $\mathrm{Zn} 2 \leftrightarrow \mathrm{Zn} 1$ & 2.0 & 0.33 & 0.0074 & -0.189 & 3.259 & -0.023 & 3.236 \\
\hline \multirow[t]{3}{*}{$1 b$} & $\mathrm{Zn} \leftrightarrow \mathrm{O}$ & 1.0 & 1.0 & 0.0259 & 6.778 & 1.936 & 0.243 & 2.179 \\
\hline & $\mathrm{Zn} \leftrightarrow \mathrm{O}$ & 3.0 & 1.0 & 0.0057 & 6.778 & 1.946 & 0.036 & 1.982 \\
\hline & $\mathrm{Zn} \leftrightarrow \mathrm{Zn}$ & 3.0 & 1.0 & 0.0146 & 6.778 & 3.162 & 0.080 & 3.242 \\
\hline \multirow[t]{5}{*}{$1 \mathrm{c}$} & $\mathrm{Zn} \leftrightarrow \mathrm{O}$ & 2.0 & 1.0 & 0.0035 & 6.172 & 1.999 & 0.064 & 2.064 \\
\hline & $\mathrm{Zn} \leftrightarrow \mathrm{O}$ & 1.0 & 1.0 & 0.0030 & 6.172 & 2.005 & -0.042 & 1.964 \\
\hline & $\mathrm{Zn} \leftrightarrow \mathrm{O}$ & 1.0 & 1.0 & 0.0030 & 6.172 & 2.011 & -0.042 & 1.969 \\
\hline & $\mathrm{Zn} \leftrightarrow \mathrm{C}$ & 1.0 & 1.0 & 0.0040 & 6.172 & 2.959 & -0.011 & 2.948 \\
\hline & $\mathrm{Zn} \leftrightarrow \mathrm{C}$ & 1.0 & 1.0 & 0.0040 & 6.172 & 2.981 & -0.011 & 2.970 \\
\hline
\end{tabular}

[a] Parameters were fixed during the iteration; $E_{0}$ : passive electron reduction factor, $\sigma^{2}$ : Debye-Waller-like factor, $R_{\text {eff }}$ : initial path length, $\Delta R$ : change in path length, $R$ : final path length.

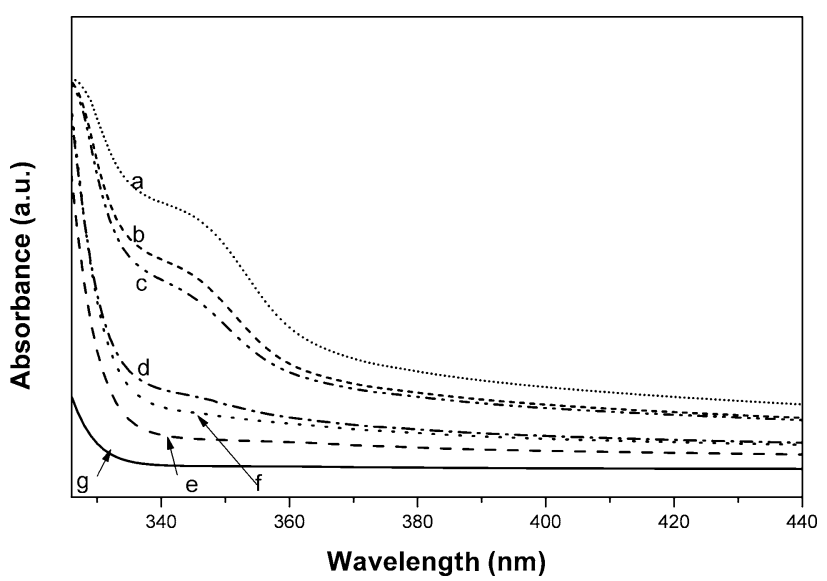

Figure 3. UV/Vis spectra after: (a) 290, (b) 260, (c) 230, (d) 110, (e) 80 , (f) 50 , (g) 0 min of reflux time.

\section{Synthesis and Characterisation of Nanocrystalline $\mathrm{ZnO}$ in Different Dispersing Media}

\section{Preparation without Heating: Effect of the Heating Step}

$\mathrm{ZnO}$ suspensions were prepared starting from $\mathrm{Zn}(\mathrm{acac})_{2}$ in four different solvents (ethanol, water, glycerol and 1,2propanediol) and by heating at $80^{\circ} \mathrm{C}$ for two hours.

The composition, the microstructure and the morphology of all obtained samples were investigated. For the specimen prepared starting from ethanol suspension, the effect of the reflux step was also taken into account.

It was found that longer heating times did not affect the average size of the nanoparticles, as particles heated for 2 or 6 hours practically displayed the same dimension. Furthermore, it is worth noting that different replicates of the same experiment lead to identical results both in terms of composition and structure as well as of average particle size, thus confirming the reproducibility of the route.
On the other hand, the absence or presence of the heating step was proven to dramatically affect the evolution of the systems in ethanol. In fact, suspensions prepared without heating, but just stirring the mixture of $\mathrm{Zn}(\mathrm{acac})_{2}$ and $\mathrm{NaOH}$ at room temp., yielded a precipitate that was a mixture of $\mathrm{ZnO}$ (wurtzite) and a further $\mathrm{Zn}$-based compound with reflections at lower angles and a high amount of organic residual (as revealed by XPS and IR). In this case IR also revealed the band of acetylacetonate and the presence of $\mathrm{OH}$ groups, although the XRD pattern was completely different from that of $\mathrm{Zn}(\mathrm{acac})_{2}$ (see Figure S1 in Supporting Information).

SEM micrographs of the $\mathrm{ZnO}$ powders obtained without the inclusion of a thermal step (see Figure 4) show a very peculiar morphology characterised by a combination of microrods and large, more compact, aggregates.
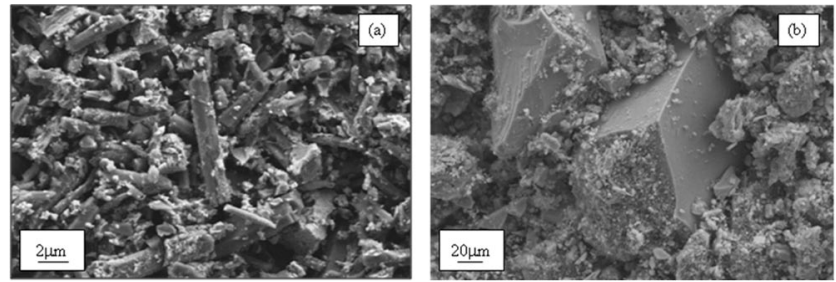

Figure 4. SEM micrographs of $\mathrm{ZnO}$ powders before thermal treatment collected at high (a) and low (b) magnification level.

The EDX spectra (see Figure 5) of these systems revealed that the $\mathrm{C}$ signal corresponding to the undecomposed acetylacetonate groups, as confirmed by IR and XPS analysis, is still present in the material. Furthermore, EDX mapping investigations (data not shown) evidence that organic residuals are predominantly located on the microrods, while the compact macroaggregates are predominantly composed of $\mathrm{ZnO}$ matrixes. 


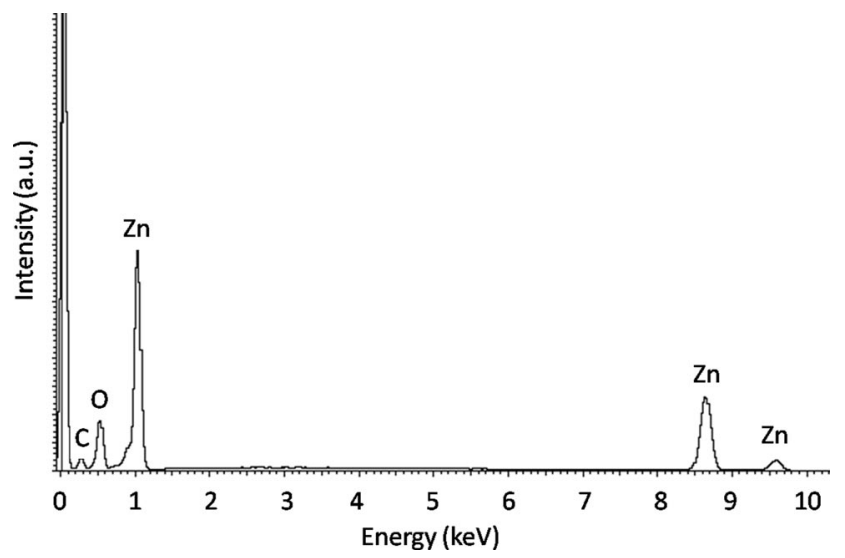

Figure 5. EDX spectrum of $\mathrm{ZnO}$ powders before thermal treatment.

The decomposition of acetylacetonate to acetate, as suggested by Inubushi et al., ${ }^{[20]}$ was ruled out on the basis of the XRD pattern (see Figure S1).

\section{Preparation with Heating Step}

In a first approximation, we can consider the diffusion as inversely related to the viscosity by the well known StokesEinstein-Sutherland equation. ${ }^{[22]}$ It is expected that, other conditions being equal, an increase of the viscosity of the dispersing medium could lead to a decrease of the diffusion coefficient and thus affect the growth rate of the colloidal particles.

One of the aims of the present study was to point out whether the different viscosities and dielectric constants of the solvents could either slow down or accelerate the growth rate of the colloidal particles and affect the distribution of their sizes.

The growth mechanism of $\mathrm{ZnO}$ nanocrystals in suspension, typically obtained by reaction of zinc acetate with sodium hydroxide, has been the topic of several extended investigations, ${ }^{[9 b, 23]}$ which have pointed out that the growth is affected not only by the composition of the suspension, but also, as expected, by the temperature of the suspension. Although there are reports on non-Ostwald ripening growth mechanisms, ${ }^{[23 a, 24]}$ the almost universally accepted mechanism for growth of semiconductor nanocrystals is the dif- fusion-limited Ostwald ripening. ${ }^{[25,26]}$ In the past, it has been reported ${ }^{[25 \mathrm{c}, 23 \mathrm{f}]}$ that the growth of $\mathrm{ZnO}$ in water, on the basis of the dependence of average diameter on time ( $d$ $\approx t^{1 / 3}$ ), follows the common accepted Ostwald ripening path. However, more recent contributions, ${ }^{[23 a]}$ based on the evaluation of the dependence of the growth kinetics on temperature and composition, invalidate this oversimplified approach and show instead a dependence which is different from that expected in an exclusively diffusion-limited scenario.

In particular, more recent reports have evidenced that the growth of $\mathrm{ZnO}$ colloids can be explained as determined by the occurrence of different events and can be interpreted as an intermediate between the two limiting models, that is diffusion-limited Ostwald ripening and kinetically controlled growth.

In our case, the molar ratio between zinc acetylacetonate and $\mathrm{NaOH}$ was kept constant (1:2), as well as the reaction temperature $\left(80^{\circ} \mathrm{C}\right)$. The only difference between the four routes is the nature of the suspension media used, which are characterised by different viscosity, dielectric constant and $\mathrm{p} K_{\mathrm{a}}$, as summarised in Table 2.

The powders isolated by filtering and drying the suspensions of $\mathrm{ZnO}$ were characterised by TEM and XRD, providing information on structure and crystallite size. As mentioned, different batches always present the same XRD patterns, thus confirming the reproducibility of the preparative route.

The solids precipitated after the reflux show the typical XRD patterns of hexagonal wurtzite zinc oxide, ${ }^{[27]}$ whereas no reflections ascribed to residual zinc acetylacetonate were detected. In Figure 6, the diffractograms of the four solids are plotted. The broadened reflections can be ascribed to the presence of nanosized domains. ${ }^{[28]}$

The most striking result is the broadening of the peaks in the samples obtained with 1,2-propanediol and ethanol. This is evidenced also by the (200), (112) and (201) peaks merging into a single broad signal. The widening of the diffraction peaks is indicative of a reduction in crystallite size. The average sizes of the crystallites were quantified by the Scherrer equation ${ }^{[28]}$ (see Table 2 and also Table S1 in Supporting Information). For example, the size of crystallites in the direction normal to the (101) planes was 33 and $22 \mathrm{~nm}$ for the samples obtained by water and glycerol,

Table 2. Dielectric constants, viscosities and $\mathrm{p} K_{\mathrm{a}}$ values for the different solvents used for synthesis of nanostructured $\mathrm{ZnO}$ and corresponding average diameters as determined by TEM and XRD analyses.

\begin{tabular}{|c|c|c|c|c|c|}
\hline Sample & $\varepsilon$ & $\eta(\mathrm{cp})$ & $\mathrm{p} K_{\mathrm{a}}$ & $\begin{array}{l}\text { Average diameter } \\
\text { (TEM) }(\mathrm{nm})\end{array}$ & $\begin{array}{l}\text { Average diameter } \\
\text { (XRD) (nm) }\end{array}$ \\
\hline ZnO_EtOH & $25.0\left(25^{\circ} \mathrm{C}\right)$ & $\begin{array}{l}0.504\left(70^{\circ} \mathrm{C}\right) \\
1.2\left(20^{\circ} \mathrm{C}\right)\end{array}$ & 15.9 & $6 \pm 2$ & $8 \pm 2$ \\
\hline ZnO_Gly & $42.5\left(25^{\circ} \mathrm{C}\right)$ & $\begin{array}{c}629\left(30^{\circ} \mathrm{C}\right) \\
1490\left(20^{\circ} \mathrm{C}\right)\end{array}$ & 14.15 & $>200$ & $21 \pm 9$ \\
\hline ZnO_Prop & $37.0\left(20^{\circ} \mathrm{C}\right)$ & $\begin{array}{c}3.02\left(80^{\circ} \mathrm{C}\right) \\
19.9\left(20^{\circ} \mathrm{C}\right)\end{array}$ & 14.22 & $6 \pm 2$ & $7 \pm 1$ \\
\hline $\mathrm{ZnO}{ }_{-} \mathrm{H}_{2} \mathrm{O}$ & $78.5\left(25^{\circ} \mathrm{C}\right)$ & $\begin{array}{c}0.3547\left(80^{\circ} \mathrm{C}\right) \\
1.002\left(20^{\circ} \mathrm{C}\right)\end{array}$ & 15.75 & 20-200 & $31 \pm 9$ \\
\hline
\end{tabular}




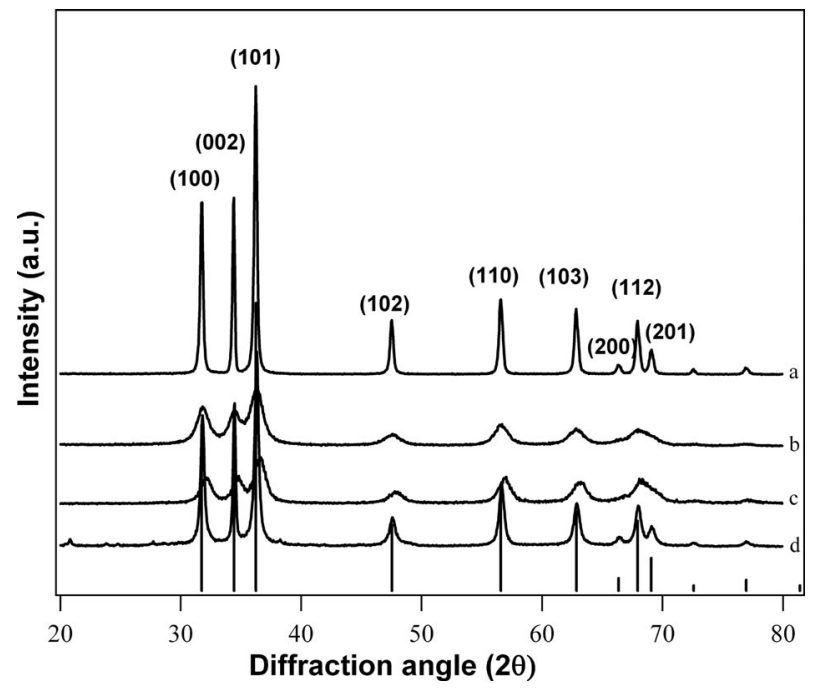

Figure 6. X-ray diffraction pattern of nanostructured $\mathrm{ZnO}$ prepared with (a) water, (b) ethanol, (c) 1,2-propanediol and (d) glycerol. The indexing and, on the bottom, the bars correspond to the hexagonal structure of $\mathrm{ZnO}$.

whereas it was much decreased in the case of samples prepared with ethanol and 1,2-propanediol, that is 8 and $7 \mathrm{~nm}$, respectively (vide infra). These values are in agreement with those obtained by TEM, thus suggesting that each fine $\mathrm{ZnO}$ particle consists of a single wurtzite crystallite. It is worth noting that along the direction normal to the (110) planes the crystallite sizes for the samples obtained in ethanol and 1,2-propanediol were 7 and $6 \mathrm{~nm}$, respectively, in good agreement with those reported above for the (101) planes. These results suggest a rather isotropic crystallite shape. On the other hand, as far as crystallite size is concerned, samples prepared in water or glycerol showed a certain degree of anisotropy. If the crystallite size along the normal to the (110) planes was compared to that assessed on the basis of (101) peaks, a sharp decrease was noted, with values of $23 \mathrm{~nm}$ for the sample obtained with water and $17 \mathrm{~nm}$ for that produced in glycerol.

These differences in the size of the crystallites observed in the different dispersing media were ascribed to the different growth mechanisms occurring in alcoholic and aqueous environments as a consequence of the different chemicophysical features of the different solvents used.

TEM measurements confirmed XRD results. All samples synthesised in ethanol feature a particle dimension ranging from 6 to $9 \mathrm{~nm}$, whereas the average diameters obtained in the other dispersing media are reported in Table 2. Primary particles do not coalesce, but just aggregate, and show a narrow size distribution, that is a low polydispersity.

Figure 7 shows the different morphologies obtained in the different solvents. In particular, Figure 7 (a) shows an example of particles obtained in EtOH. For each agglomerate, selected area electron diffractions (SAED) were collected in order to investigate the crystalline nature of samples. SAED were integrated using the ProcessDiffraction program. ${ }^{[29]}$

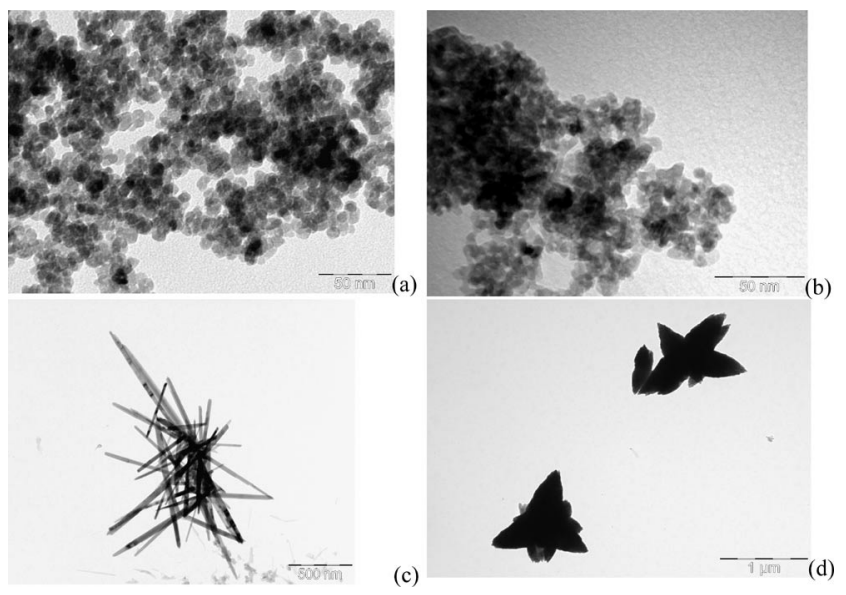

Figure 7. TEM micrographs of $\mathrm{ZnO}$ _EtOH nanoparticles (a), ZnO_Prop nanoparticles (b), $\mathrm{ZnO}_{-} \mathrm{H}_{2} \mathrm{O}$ showing needle-like structures (c) and star-like morphology typical of $\mathrm{ZnO}$ _Gly (d).

All SAED were indexed as hexagonal zinc oxide, space group P63mc (Figure 8, a), in agreement with XRD data. EDXS analyses show as principal elements zinc and oxygen (Figure 8, b), whereas the presence of carbon and copper are due to the TEM grid used for sample preparation.
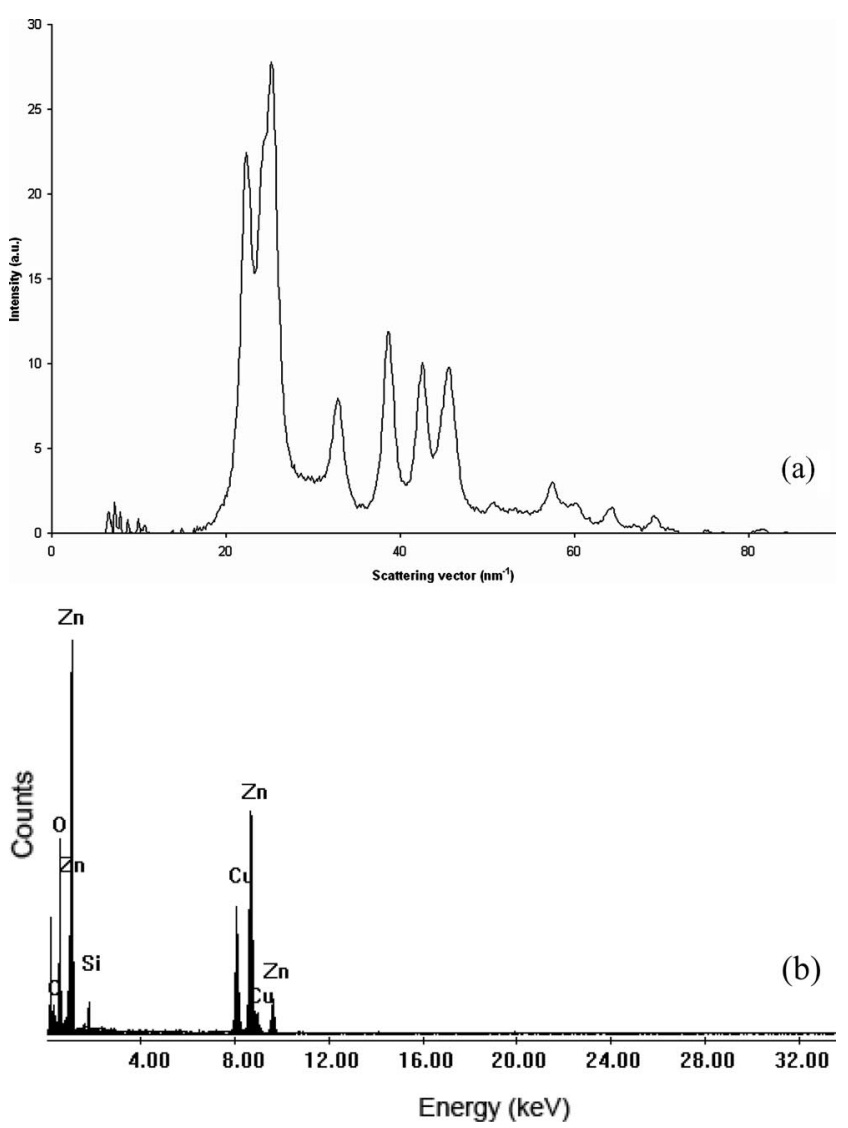

Figure 8. (a) SAED of $\mathrm{ZnO} \_$EtOH nanoparticles and (b) EDXS of $\mathrm{ZnO}$ _EtOH nanoparticles.

To obtain statistical information about the size distribution, image analysis was performed. Because of the tendency of nanoparticles to agglomerate, it is impossible to 
perform image analysis on micrographs like Figure 7a, therefore dark field images were used for this purpose. The dark field allows only some particles to be highlighted, to avoid the problem of particle superimposition in images of agglomerates and also to improve the image contrast. Obviously the information about the majority of particles is lost, but the lower particle superimposition allows the analysis to be performed. The average diameter of ethanol samples ranges between 6 and $9 \mathrm{~nm}$ and the distributions are quite close to the mean value.

Concerning the samples synthesised in 1,2-propanediol (see Figure 7, b), the average particle diameter ranges from 6 to $10 \mathrm{~nm}$, in agreement with XRD data and the distributions are quite close to the mean values also in this case.

All the collected SAED were indexed as hexagonal $\mathrm{ZnO}$. EDXS spectra (data not shown) of the samples confirm zinc and oxygen as the main components. Traces of sodium were also detected. In these samples, the presence of sodium was explained by the fact that the $\mathrm{Na}^{+}$counterions are attracted by the hydroxy ions around the nanocrystals forming a kind of virtual capping layer.

The samples synthesised in water indeed display a needlelike morphology (Figure 7, c) with thickness in the order of $20-100 \mathrm{~nm}$ and length more than $500 \mathrm{~nm}$. Electron diffraction shows that the crystalline phase is hexagonal zinc oxide (see Figure S2 of Supporting Information).

Concerning the sample synthesised in glycerol, it features a star-like structure with particle dimensions larger than $200 \mathrm{~nm}$ (Figure 7, d). Electron diffraction shows that the crystalline phase is still hexagonal zinc oxide. EDXS analysis again displays zinc, sodium and oxygen as the main components (data not shown).

The Scherrer formula applied to XRD data revealed an average crystallite size of $(21 \pm 9) \mathrm{nm}$, suggesting that the larger agglomerates observed in TEM micrographs are likely constituted by smaller crystallites retaining their integrity.

The morphology of the heated samples is very different from that observed in the samples prepared at room temperature. As can be observed in Figure $9(a, b)$ and in the corresponding EDX spectrum (Figure 10), the heating step process also results in a dramatic change in the sample morphology with respect to those obtained at room temperature.

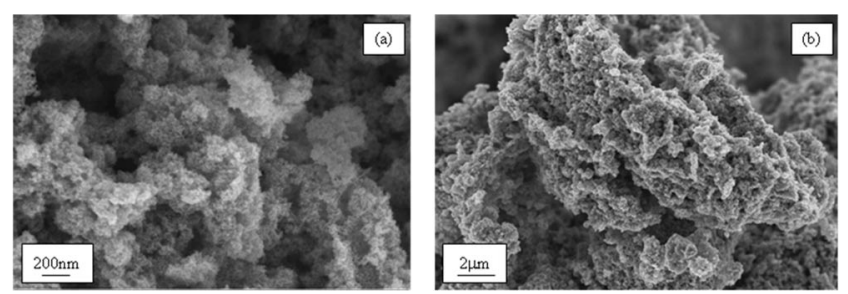

Figure 9. SEM micrographs of $\mathrm{ZnO}$ powders after reflux thermal treatment collected at high (a) and low (b) magnification level.

SEM pictures of $\mathrm{ZnO}$ powders obtained after the reflux thermal treatment at $80^{\circ} \mathrm{C}$, collected at high and low magnification level (Figure 9), confirm the dramatic influence

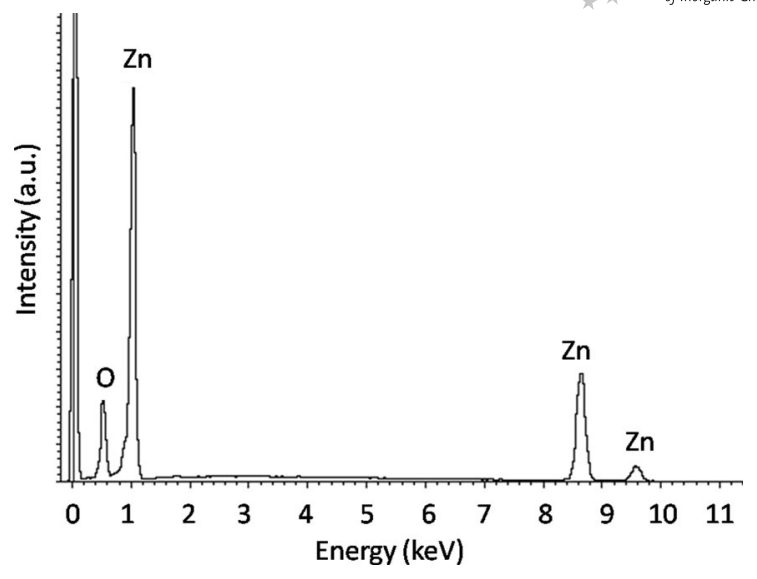

Figure 10. EDX spectrum of $\mathrm{ZnO}$ powders after reflux thermal treatment.

of thermal procedure on the system morphology. In fact, inspection of Figure 9 shows the formation of a highly porous material characterised by small nanoaggregates, as confirmed also by TEM investigation. The EDX compositional analysis of these systems (see Figure 10) proves both the complete disappearance of the organic residuals, found in the untreated powders, and the high purity of these $\mathrm{ZnO}$ nanoaggregates.

XPS measurements were performed on $\mathrm{ZnO}$ obtained from 1,2-propanediol, water, ethanol and glycerol to get information about the composition and the chemical environment of zinc and oxygen atoms. O1s peaks were deconvoluted using commercial software. The $\mathrm{BE}$ values for the $\mathrm{Zn} 2 \mathrm{p}_{3 / 2}$ and $\mathrm{O} 1 \mathrm{~s}$ regions, along with the $\mathrm{O} / \mathrm{Zn}$ atomic ratios, are summarised in Table 3.

Table 3. $\mathrm{BE}\left(\mathrm{eV}\right.$ ) values for $\mathrm{Zn} 2 \mathrm{p}_{3 / 2}$ and $\mathrm{O} 1 \mathrm{~s}$ and atomic percentage ratios $\mathrm{O} / \mathrm{Zn}$ relative to the four $\mathrm{ZnO}$ samples synthesised from different media. Values of $\mathrm{BE}$ were corrected considering charging effects.

\begin{tabular}{lcccc}
\hline $\mathrm{BE}(\mathrm{eV})$ & $\mathrm{EtOH}$ & 1,2-Propanediol & $\mathrm{H}_{2} \mathrm{O}$ & Glycerol \\
\hline $\mathrm{Zn} 2 \mathrm{p} 3 / 2(\mathrm{eV})$ & 1021.3 & 1021.1 & 1021.1 & 1021.6 \\
$\mathrm{O} 1 \mathrm{~s}$ & 529.8 & 530.0 & 529.4 & 530.4 \\
& 530.8 & 531.5 & 530.9 & 531.7 \\
& 532.4 & 532.9 & 532.2 & 532.9 \\
$\mathrm{O} / \mathrm{Zn}($ atomic $\%)$ & 1.1 & 2.0 & 1.1 & 1.3 \\
\hline
\end{tabular}

In Figure $11(\mathrm{a}, \mathrm{b})$, the $\mathrm{Zn} 2 \mathrm{p}$ region and the deconvolution of $\mathrm{O} 1 \mathrm{~s}$ are reported for $\mathrm{ZnO}$ obtained from ethanol. For the other samples, see the Supporting Information (Figures $\mathrm{S} 3, \mathrm{~S} 4, \mathrm{~S} 5$ ).

For $\mathrm{ZnO}$, tabulated $\mathrm{BE}$ values for $\mathrm{Zn} 2 \mathrm{p}_{3 / 2}$ are between 1021.1 and $1022.4 \mathrm{eV}$ while for $\mathrm{Zn}(\mathrm{OH})_{2}$ the value is $1022.7 \mathrm{eV}^{[30,32,34,35]}$ The experimental values (see Table 3 ) for the four samples are in the range 1021.1-1021.6 eV, values similar to zinc oxide, whereas they are quite different from those reported for $\mathrm{Zn}(\mathrm{OH})_{2}$. However, the deconvolution of O1s in three components reveals the presence of $\mathrm{OH}$ species at the surface. Peak components corresponding 

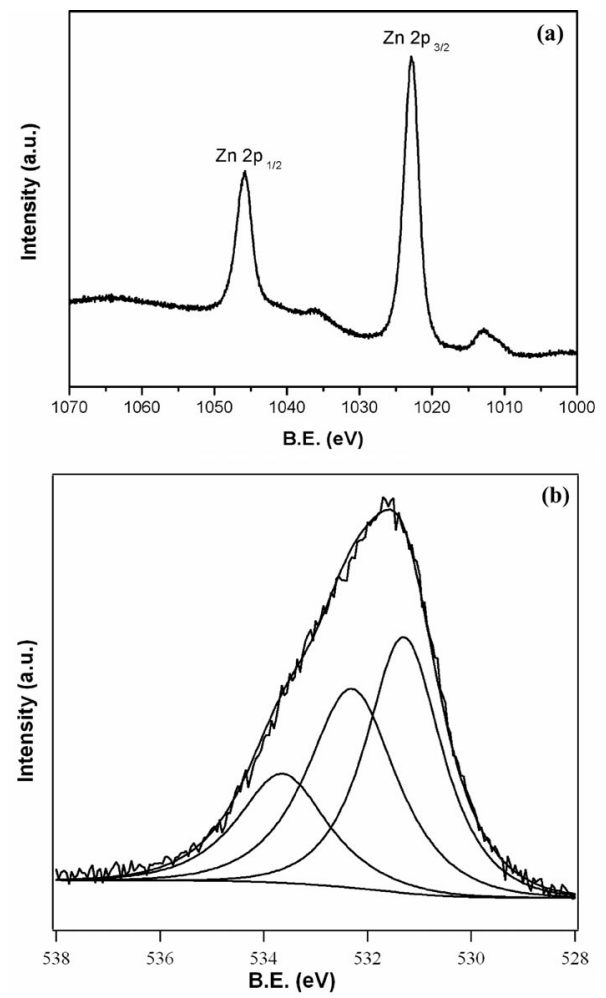

Figure 11. (a) $\mathrm{Zn} 2 \mathrm{p}$ region for $\mathrm{ZnO} E \mathrm{EtOH}$; (b) deconvolution of $\mathrm{O} 1 \mathrm{~s}$ region for $\mathrm{ZnO}$ _EtOH.

to $\mathrm{OH}$ were at $530.8,531.5,530.9$ and $531.7 \mathrm{eV}$ for samples obtained from ethanol, 1,2-propanediol, water and glycerol, respectively.

The presence of $\mathrm{OH}$ groups is confirmed also by FTIR analysis, which reveals for all the samples the typical broad band at $3390-3370 \mathrm{~cm}^{-1}$ of the $\mathrm{O}-\mathrm{H}$ stretching (Figure 12).

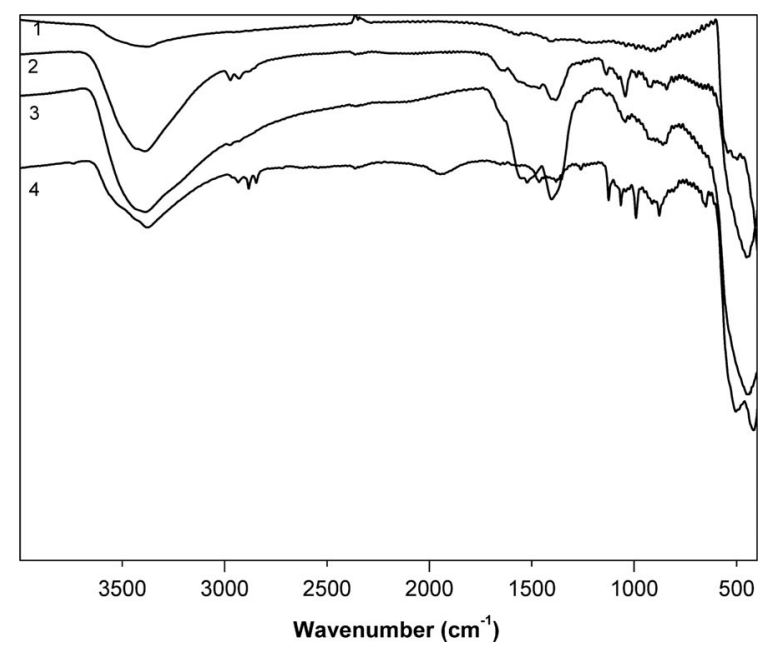

Figure 12. FTIR spectra for: (1) $\mathrm{ZnO}_{-} \mathrm{H}_{2} \mathrm{O}$, (2) $\mathrm{ZnO}$ _Prop, (3) ZnO_EtOH, (4) ZnO_Gly.

As can be seen in Table 3, the $\mathrm{O} / \mathrm{Zn} \%$ atomic ratios are quite close to the stoichiometric ratio (1), except in the case of 1,2-propanediol.
The atomic percentage of carbon is between $35 \%$ and $40 \%$ for samples in ethanol, 1,2-propanediol and glycerol, while for water the percentage is lower, $20 \%$, as confirmed by elemental analysis. These are typical values for adventitious carbon but, as evidenced by FTIR, the presence of organic ligand 2,4-pentanedionate from the precursor must be taken into account.

The specific surface area of the $\mathrm{ZnO}$ nanoparticles synthesised in $\mathrm{EtOH}$, as determined by BET measurements, was $(64 \pm 1) \mathrm{m}^{2} / \mathrm{g}$, with an average pore diameter of $78 \AA$.

\section{Surface Acidities}

Concerning the $\mathrm{ZnO}$ prepared in ethanol, the surface acidic active sites were investigated (with DRIFT spectroscopy) by chemisorbing pyridine. The DRIFT spectra, recorded after exposure of the $\mathrm{ZnO}$ prepared in ethanol to a pyridine/argon mixture at room temperature, and successively to an argon stream for different periods of time, are shown in Figure 13. Inspection of the spectral region of the ring-stretching modes reveals the presence of several contributions at 1441, 1580, 1589 and $1611 \mathrm{~cm}^{-1}$ (Figure 13, a). Comparison with literature data suggests the existence of different kinds of pyridine- $\mathrm{ZnO}$ interactions. The contributions at lower wavenumber are consistent with the pyridine H-bound to the surface hydroxy groups (1441, 1580 and $1589 \mathrm{~cm}^{-1}$ ). The peak at higher wavenumber is ascrib-
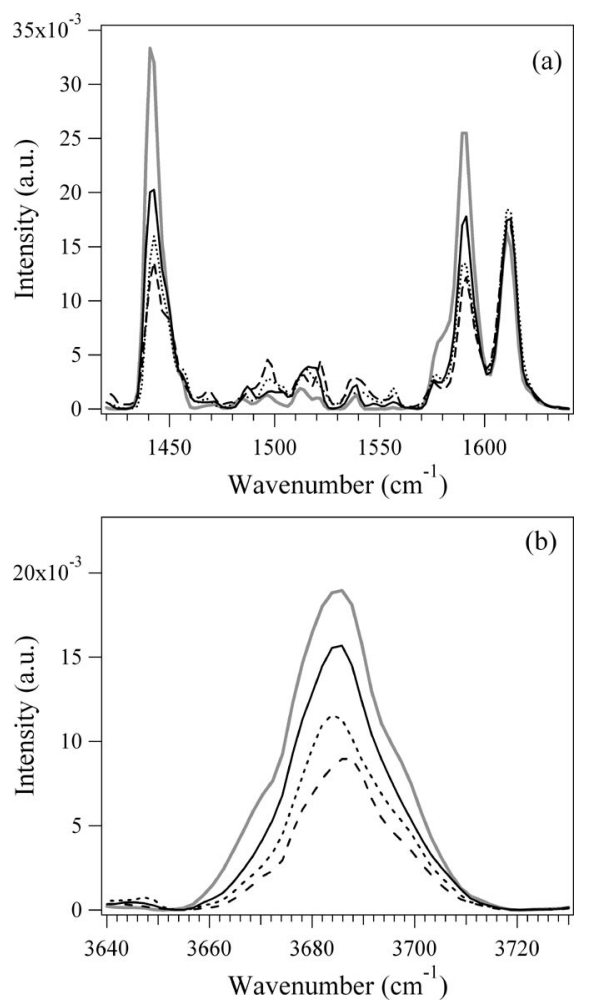

Figure 13. DRIFT spectra obtained at room temp. after exposing the $\mathrm{ZnO}$ prepared in ethanol to pyridine + Ar (gray line) and successively to Ar for $7 \mathrm{~min}$ (black line), $15 \mathrm{~min}$ (dotted line) and 25 min (dashed line). (a) Pyridine stretching modes spectral region. (b) $\mathrm{O}-\mathrm{H}$ stretching spectral region. 
able to pyridine interacting with Lewis acidic sites distributed on the $\mathrm{ZnO}$ surface. ${ }^{[31]}$

After evacuation with Ar flow at room temp. the bands due to $\mathrm{H}$-bound pyridine progressively decrease, while the contribution at $1611 \mathrm{~cm}^{-1}$ remains almost unchanged, suggesting that the pyridine coordinated to Lewis acidic sites is very strongly tied up. This confirms the presence of medium- to high-strength acidic sites on the $\mathrm{ZnO}$ surface.

Parallel to the above spectral changes, pyridine interaction brings about a severe perturbation of the surface hydroxy groups by creating a rather broad adsorption $3686 \mathrm{~cm}^{-1}$ (Figure 13, b). The behaviour as a function of evacuation time suggests that the pyridine interacting by $\mathrm{H}$ bond is mainly responsible for the perturbation.

\section{Hydrolysis and Condensation towards $\mathrm{ZnO}$}

As far as the initial formation of the first $\mathrm{ZnO}$ "seeds" is concerned, as already mentioned, neither XAFS nor UV/ Vis provided evidence of the formation of polynuclear species.

In the quoted paper by Pinna, Niederberger et al., ${ }^{[10 d]}$ the authors prepare $\mathrm{ZnO}$ nanoparticles starting from zinc acetylacetonate and benzylamine. Also in the reported study, as in the present case, a nonaqueous route is used to produce nanostructured zinc oxide. In the paper by Pinna et al., the zinc acetylacetonate is nucleophilically attacked by benzylamine, and a reaction mechanism based on the $\mathrm{C}-\mathrm{C}$ cleavage of acetylacetonate is proposed on the basis of GC-MS results. In the present case, the nucleophilic attack is instead carried out by $\mathrm{NaOH}$. Beside the similarities (nonaqueous medium, nucleophilic attack, use of zinc acetylacetonate as precursors), there are however some relevant differences such as the solvothermal reaction conditions applied by Niederberger et al. ${ }^{[10 \mathrm{~d}]}$ as well as the use of benzylamine as solvent, which means it cannot be inferred that the same mechanism occurs also in our case. In the study presented in this paper, the role of the dispersing medium seems to be pivotal.

Although it is not yet clear how, the nature of the solvent strongly affects the size and the morphology of the particles. In fact, the average particle diameter obtained in the different dispersing media (see Table 3 ) is small (about $8 \mathrm{~nm}$ ) in $\mathrm{EtOH}$ and 1,2-propanediol and larger in the case of water and glycerol (31 and $21 \mathrm{~nm}$, respectively). Moreover, whereas in the case of the former two media, spherical and well separated nanoparticles are formed, in the case of water needle-like crystals consisting of crystallite of about $21 \mathrm{~nm}$, with an overall size of about $200 \mathrm{~nm}$, are observed. In the case of glycerol, star-like particles with an average crystallite size of $21 \mathrm{~nm}$ can be seen.

As far as the nucleation and growth fashion and particle size in the different media are concerned, a rationalisation relating the chemicophysical nature of the different media on the mechanism of hydrolysis and condensation is quite challenging and did not provide any satisfactory conclusion. In Table 2, three relevant chemicophysical properties $\left(\mathrm{p} K_{\mathrm{a}}\right.$, dielectric constant and viscosity at room and final temperatures) are reported for the four media. As a matter of fact, no relationship among viscosity, acidity, dielectric constant and crystallite size could be observed, which would be expected in the case of an oversimplified growth model based only on diffusion. On the basis of these considerations, it becomes quite difficult to single out which solvent characteristic (other conditions being equal) is actually responsible for determining the different morphologies, sizes and size distributions observed, although it can be hypothesised that a major role is played by the dielectric constant.

\section{Conclusions}

In the present work we describe an easy, reproducible, cost-effective and fast synthesis route for the production of $\mathrm{ZnO}$ colloids. The synthesis was carried out starting from $\mathrm{Zn}(\mathrm{acac})_{2}$ in four different solvents to investigate the effects of the physicochemical properties of the dispersing medium on the nucleation and growth of the oxide nanostructures.

Formation of hexagonal $\mathrm{ZnO}$ nanostructures was observed in all cases, whereas the different nanoscopic architectures and morphologies were evidenced as a function of the different media. On the surface of the nanoparticles, the presence of acetylacetonate residuals was detected. The heating step was evidenced to play an important role in affording the formation of pure $\mathrm{ZnO}$. The investigation of the kinetics of the process by time-resolved EXAFS was very difficult due to the coexistence of different species and different equilibria in solution, delivering only an averaged picture.

Moreover, this study has evidenced that the combination of complementary analytical methods with different selectivity, sensitivity, time and spatial resolution is mandatory to collect information on the process to obtain $\mathrm{ZnO}$ nanoparticles. This study has also outlined that the examined system is too complicated to unambiguously determine the sequence of chemical events involved in the process. As a final remark, the proper combination of methods delivering complementary and mutually integrating information is fundamental to avoid errors and misinterpretation of data arising from separate experiments.

\section{Experimental Section}

Chemicals: Zinc 2,4-pentanedionate purchased from Aldrich was anhydrified under vacuum on $\mathrm{P}_{2} \mathrm{O}_{5}$ for $48 \mathrm{~h}$. Sodium hydroxide, ethanol, 1,2-propanediol and 1,2,3-propanetriol (glycerol) were purchased from Aldrich, Milan, Italy and used without further purification. Anhydrous KBr was purchased from Merck, Germany.

Chemicophysical Characterisation of $\mathbf{Z n}(\mathbf{a c a c})_{2}$ : FTIR $(\mathrm{KBr}): \tilde{v}=$ 3000 (w), 2966 (w), 2919 (w), 1591 [ $(\mathrm{C}=\mathrm{O}), \mathrm{s}], 1520$ [v(C=C), s], $1444\left[\delta\left(\mathrm{CH}_{3}\right), \mathrm{sh}\right], 1403\left[\delta\left(\mathrm{CH}_{3}\right), \mathrm{s}\right], 1367(\mathrm{~s}), 1259\left(\mathrm{C}-\mathrm{CH}_{3}\right.$ and $\mathrm{C}=\mathrm{C}, \mathrm{s}), 1195\left[\delta\left(\mathrm{CH}_{3}\right), \mathrm{w}\right], 1018(\mathrm{~m}), 926(\mathrm{~m}), 806(\mathrm{w}), 763[\delta(\mathrm{C}-$ $\mathrm{H}), \mathrm{m}], 670[\mathrm{v}(\mathrm{Zn}-\mathrm{O}), \mathrm{w}], 553[\mathrm{v}(\mathrm{Zn}-\mathrm{O}), \mathrm{w}], 418[\mathrm{v}(\mathrm{Zn}-\mathrm{O}), \mathrm{m}] \mathrm{cm}^{-1}$. ${ }^{1} \mathrm{H}$ NMR $\left(\mathrm{CD}_{3} \mathrm{CD}_{2} \mathrm{OD}, 298 \mathrm{~K}\right): \delta=1.92\left(\mathrm{~s}, \mathrm{CH}_{3}\right), 5.32(\mathrm{~s}, \mathrm{CH})$ ppm. ${ }^{13} \mathrm{C}$ NMR $\left(\mathrm{CD}_{3} \mathrm{CD}_{2} \mathrm{OD}, 298 \mathrm{~K}\right): \delta=28.24\left(\mathrm{CH}_{3}\right), 100.58$ 
$(\mathrm{CH}), 190.78(\mathrm{C}=\mathrm{O})$ ppm. XPS analysis (BE in $\mathrm{eV}$ and atomic percentages): $\mathrm{C} 1 \mathrm{~s}$ : $284.8 \mathrm{eV}$ (52.2\%); O1s $531.5 \mathrm{eV}$ (32.7\%); Zn2p $1021.6 \mathrm{eV}(15.1 \%)$. XRD: see Supporting Information, Figure S1. $\mathrm{C}_{10} \mathrm{H}_{14} \mathrm{O}_{4} \mathrm{Zn}$ (281.64): calcd. C 45.5, H 5.35; found C 45.12, H 5.51.

\section{Procedures}

Synthesis of ZnO in Ethanol (ZnO_EtOH): Zn(acac) 2 (2.13 g, $8.1 \mathrm{mmol})$ was dissolved in ethanol $(100 \mathrm{~mL})$ whilst stirring and heating. $\mathrm{NaOH}$ ( 2 equiv.) was added from a solution of $\mathrm{NaOH}$ $(0.44 \mathrm{M})$ in ethanol. The resulting suspension was stirred at $80^{\circ} \mathrm{C}$ for $6 \mathrm{~h}$, then cooled to room temperature. After cooling, the fine precipitate was collected by centrifugation of the suspension at $4500 \mathrm{rpm}$ for $7 \mathrm{~min}$ and then washed three times with ethanol. The precipitate was dried under vacuum for $24 \mathrm{~h}$. $\mathrm{ZnO}$ _EtOH: found C $1.00 ; \mathrm{H} 0.45$.

Synthesis of $\mathrm{ZnO}$ in 1,2-Propanediol (ZnO_Prop): $\mathrm{Zn}(\mathrm{acac})_{2}$ $(2.10 \mathrm{~g}, 8.0 \mathrm{mmol})$ was dissolved in 1,2-propanediol $(100 \mathrm{~mL})$ whilst stirring. $\mathrm{NaOH}$ (2 equiv.) was added from a solution of $\mathrm{NaOH}(0.44 \mathrm{M})$ in ethanol. The resulting suspension was stirred at $80^{\circ} \mathrm{C}$ for $6 \mathrm{~h}$, then cooled to room temperature. After cooling, the fine precipitate was collected by centrifugation of the suspension at $4000 \mathrm{rpm}$ for $15 \mathrm{~min}$ and then washed three times with ethanol. The precipitate was dried under vacuum for $24 \mathrm{~h}$. ZnO_Prop: found C 4.89, H 0.83 .

Synthesis of $\mathrm{ZnO}$ in Glycerol (ZnO_Gly): $\mathrm{Zn}(\mathrm{acac})_{2}$ (2.12 g, $8.04 \mathrm{mmol})$ was dissolved in glycerol $(100 \mathrm{~mL})$ whilst stirring and heating. $\mathrm{NaOH}$ ( 2 equiv.) was added from a solution of $\mathrm{NaOH}$ $(0.44 \mathrm{M})$ in ethanol. The resulting suspension was stirred at $80^{\circ} \mathrm{C}$ for $6 \mathrm{~h}$, then cooled to room temperature. After cooling, the fine precipitate was collected by centrifugation of the suspension at $4500 \mathrm{rpm}$ for $15 \mathrm{~min}$ and then washed three times with ethanol. The precipitate was dried under vacuum for $24 \mathrm{~h}$. $\mathrm{ZnO}$ _Gly: found C 2.37 ; H 0.66 .

Synthesis of $\mathbf{Z n O}$ in Water $\left(\mathrm{ZnO}_{-} \mathbf{H}_{2} \mathbf{O}\right): \mathrm{Zn}(\mathrm{acac})_{2}(2.12 \mathrm{~g}$, $8.04 \mathrm{mmol})$ was suspended in distilled water $(100 \mathrm{~mL})$ whilst stirring and heating. $\mathrm{NaOH}$ ( 2 equiv.) was added from a solution of $\mathrm{NaOH}(0.44 \mathrm{M})$ in water. The resulting suspension was stirred at $80^{\circ} \mathrm{C}$ for $6 \mathrm{~h}$, then cooled to room temperature. After cooling, the fine precipitate was collected by centrifugation of the suspension at $3500 \mathrm{rpm}$ for $7 \mathrm{~min}$ and then washed three times with ethanol. The precipitate was dried under vacuum for $24 \mathrm{~h}$. $\mathrm{ZnO}_{-} \mathrm{H}_{2} \mathrm{O}$ : found C $0.41, \mathrm{H}$ traces.

FTIR Data of ZnO_EtOH: $3350[v(\mathrm{OH}), \mathrm{br}], 1554[\mathrm{v}(\mathrm{C}=\mathrm{O}), \mathrm{vw}]$, $1524[\mathrm{v}(\mathrm{C}=\mathrm{C}), 2,4$-pentanedionate, $v w], 1065(\mathrm{w}), 865(\mathrm{w}), 435$ $[\mathrm{v}(\mathrm{Zn}-\mathrm{O}), \mathrm{s}] \mathrm{cm}^{-1} \cdot{ }^{[19]}$

ZnO_Gly: $3370[v(\mathrm{OH}), \mathrm{br}], 2931[\mathrm{v}(\mathrm{C}-\mathrm{H}), \mathrm{w}], 2881[\mathrm{v}(\mathrm{C}-\mathrm{H}), \mathrm{w}]$, 2842 (w), 1930 (br, w), $1463\left[\mathrm{v}\left(\mathrm{C}-\mathrm{CH}_{3}\right)\right.$, 2,4-pentanedionate, w), $1380\left[\delta\left(\mathrm{CH}_{3}\right)\right.$, 2,4-pentanedionate, w), $1120(\mathrm{w}), 1062(\mathrm{w}), 991(\mathrm{w})$, $879(\mathrm{w}), 504(\mathrm{~s}), 420[\mathrm{v}(\mathrm{Zn}-\mathrm{O}), \mathrm{s}] \mathrm{cm}^{-1}$. ${ }^{[19]}$

ZnO_Prop: $3390\left[v(\mathrm{OH})\right.$, br] $1643(\mathrm{vw}), 1380\left[\omega, \delta\left(\mathrm{CH}_{3}\right)\right.$, 2,4-pentanedionate, br, w], 1132 (vw), 1043 (w), 919 (vw), 842 (vw), 450 $[\mathrm{v}(\mathrm{Zn}-\mathrm{O}), \mathrm{s}] \mathrm{cm}^{-1} \cdot{ }^{[19]}$

ZnO_H ${ }_{2}$ O: $3400[v(\mathrm{OH}), \mathrm{br}], 450[\mathrm{v}(\mathrm{Zn}-\mathrm{O}), \mathrm{s}] \mathrm{cm}^{-1} \cdot{ }^{[19]}$

\section{Characterisation Methods}

FTIR Analysis: FTIR experiments were performed with a NEXUS 870 FTIR (NICOLET), operating in the transmission range 400$4000 \mathrm{~cm}^{-1}$, collecting 64 scans with a spectral resolution of $4 \mathrm{~cm}^{-1}$. The measurements were recorded by dispersing the powders in anhydrous $\mathrm{KBr}$.
XPS Analysis: The powder materials were investigated by XPS with a Perkin-Elmer $\Phi$ 5600ci instrument using standard $\mathrm{Al}-K_{\alpha}$ radiation $(1486.6 \mathrm{eV})$ operating at $350 \mathrm{~W}$. The working pressure was $\leq 5 \times 10^{-8} \mathrm{~Pa}$, about $10^{-11}$ Torr. The calibration was based on the binding energy $(\mathrm{BE})$ of the $\mathrm{Au} 4 \mathrm{f}_{7 / 2}$ line at $83.9 \mathrm{eV}$ with respect to the Fermi level. The standard deviation for the BE values was $0.15 \mathrm{eV}$. The reported BE values were corrected for the BE's charging effects, assigning the $\mathrm{BE}$ value of $284.6 \mathrm{eV}$ to the $\mathrm{C} 1 \mathrm{~s}$ line of carbon. ${ }^{[32,34]}$ Survey scans were obtained in the $0-1350 \mathrm{eV}$ range (pass energy $187.5 \mathrm{eV}, 1.0 \mathrm{eV} / \mathrm{step}, 25 \mathrm{~ms} / \mathrm{step}$ ). Detailed scans (58.7 eV pass energy, $0.1 \mathrm{eV} / \mathrm{step}, 50-150 \mathrm{~ms} / \mathrm{step}$ ) were recorded for the O1s, C1s, Zn2p, ZnLMM and Na1s regions. The atomic composition, after a Shirley-type background subtraction, ${ }^{[33]}$ was evaluated using sensitivity factors supplied by Perkin-Elmer. ${ }^{[34]}$ Charge effects were partially compensated by using a charge neutraliser (flood gun). Peak assignment was carried out according to literature data. ${ }^{[32,34]}$

Elemental Analysis: Elemental analyses were obtained in the Microanalysis Laboratory of the Department of Chemistry of the University of Padova using a Fisons EA 1108 instrument.

Thermogravimetric Analysis: The thermogravimetric analyses (TGA) were performed in air on a LabSys Setarm SDT 2960 instrument in the temperature range $20-800{ }^{\circ} \mathrm{C}$ using a heating rate of $10^{\circ} \mathrm{C} / \mathrm{min}$.

UV/Vis Absorption Analysis: The UV/Vis absorption analyses were carried out using a Cary 5 UV spectrophotometer in the spectral range $340-520 \mathrm{~nm}$ (reported $320-440 \mathrm{~nm}$ ) and a quartz cuvette with a cell thickness of $1 \mathrm{~cm}$. The concentration of the analysed $\mathrm{Zn}(\mathrm{acac})_{2}$ suspension in ethanol was $0.008 \mathrm{M}$.

X-ray Diffraction: The XRD data were collected with a Bruker D8 Advance Diffractometer equipped with a Göbel mirror. The angular accuracy was $0.001^{\circ}$ and the angular resolution was better than $0.01^{\circ}$. The average crystallite sizes were calculated by means of the Scherrer formula from the most intense peaks of each spectrum. Further wide-angle X-ray diffraction patterns were recorded with a Philips X'Pert PRO diffractometer operating in the $\theta-\theta$ geometry, equipped with a graphite monochromator on the diffracted beam $\left(\mathrm{Cu}-K_{\alpha}\right.$ radiation).

TEM Analysis: Transmission electron microscopy (TEM) analysis was carried out using a Philips CM12 microscope operated at 120 $\mathrm{keV}$ and equipped with an energy dispersive X-ray spectrometer (EDXS). TEM samples were prepared starting from $\mathrm{ZnO}$ powder, ultrasonically suspended in ethanol for $5 \mathrm{~min}$. For each sample a $100-\mu 1$ suspension drop was put on a TEM carbon-coated copper grid. After solvent evaporation $\mathrm{ZnO}$ powders remained dispersed on the carbon film of the TEM grid. Samples were therefore observed in order to investigate microstructure and size distribution of particles. Several $\mathrm{ZnO}$ powders which differ for the solvent used during synthesis were analysed. In particular, six samples synthesised in ethanol, two in propylene glycol, one in water and one in glycerol were analysed. An attempt to observe the $\mathrm{ZnO}$ particles directly from synthesis solutions was carried out for three different solutions. However $\mathrm{ZnO}$ nanoparticles could not be clearly distinguished because of the sample heterogeneity and large amount of reactants

SEM Analysis: The morphology of four $\mathrm{ZnO}$ samples, prepared from different solvents as described above, and their composition were analysed using scanning electron microscopy (SEM) and EDX spectroscopy. The precipitates obtained before heating the suspen- 
sions at $80^{\circ} \mathrm{C}$ were also investigated. Measurements were performed using a Field Emission (FE-SEM) Zeiss SUPRA 40 VP and an Oxford Inca detector for EDX analysis.

DRIFT Analysis: The IR spectra were collected with a Bruker Tensor 27 spectrometer (accumulating 32 scans at a resolution of $4 \mathrm{~cm}^{-1}$ ) and displayed in Kubelka-Munk units. ${ }^{[24]}$ Prior to each experiment, the sample was loaded in the high-temperature highpressure (HTHP) cell installed in the COLLECTOR apparatus for diffuse reflectance infrared Fourier transform (DRIFT) spectroscopy from Spectra-Tech, Inc. fitted with ZnSe windows. Before measurement, the powder was kept in argon flow to eliminate water traces until a stable IR spectrum was obtained (about $1 \mathrm{~h}$ ). Then the sample was exposed to the reactive species for $7 \mathrm{~min}$ at a flow rate of about $75 \mathrm{~cm}^{3} / \mathrm{min}$. The background spectrum of the clean surface was measured for spectra correction. The HTHP chamber was filled with the pyridine vapours, flowing argon through a bubbler containing the liquid. Pyridine used for the chemisorption was taken from a commercial source (Sigma-Aldrich, spectroscopic grade) and used without further purification.

XAS Measurements and Analysis: The XAS measurements were performed at beamlines XAS at the synchrotron radiation source Angströmquelle Karlsruhe (ANKA) and E4 at Hamburger Synchrotronstrahlungslabor (HASYLAB) at Deutsches ElektronenSynchrotron (DESY) Hamburg. A Si(111) double crystal monochromator was used for energy scan and the XAS spectrum of a zinc metal foil was recorded simultaneously to the XAS measurement of the samples. EXAFS spectra of the liquid samples were measured using a Teflon sample cell and Kapton foil windows, with adjustable spacers for X-ray beam path length adjustment. The XAS data processing was performed using Athena and the EXAFS data analysis using theoretical standards from FEFF6.0 was carried out using the program Artemis. ${ }^{[37 a]}$ For all the samples, the curve fitting of the experimental data was performed in R-space from 1.5-3.7 $\AA$. In the iterative fitting procedure of the theoretical standard to the experimental spectra the amplitude factor was kept fixed at 1.0. In anhydrous $\mathrm{Zn}(\mathrm{acac})_{2}$, zinc occupies two different sites labelled as $\mathrm{Zn} 1$ and $\mathrm{Zn} 2$. The unit cell has one $\mathrm{Zn} 2$ site and two $\mathrm{Zn} 1$ sites. Obtaining a theoretical standard for this sample therefore involved the combination of EXAFS contributions from the two different zinc sites in the ratio $\mathrm{Zn} 2 / \mathrm{Zn} 1=1: 2$. All the $\mathrm{EX}$ AFS spectra were simultaneously fitted at three $k$-weightings, $k^{1}$, $k^{2}$ and $k^{3}$, and the parameters reduced $\chi^{2}$ and $R$-factor were used to compare the different fitting models. The EXAFS studies were aimed at gaining mechanistic insight into the formation of $\mathrm{ZnO}$ nanoparticles starting from $\mathrm{Zn}(\mathrm{acac})_{2}$ using ethanol medium and $\mathrm{NaOH}$. The starting material was anhydrous $\mathrm{Zn}(\mathrm{acac})_{2}$ (1a), which has, as a solid, a trimeric structure in zinc. ${ }^{[37 b]}$ In the trimeric structure, the central $\mathrm{Zn}$ atom is hexacoordinate in a distorted octahedral arrangement whereas the coordination geometry of the two terminal $\mathrm{Zn}$ atoms is distorted trigonal bipyramidal. Sample 1a was dissolved in boiling ethanol to form a clear solution of $\mathrm{Zn}(\mathrm{acac})_{2}$, which was subsequently added with an ethanol solution of $\mathrm{NaOH}$ (1c). The EXAFS measurements were carried out under similar conditions, but employing zinc acetate instead of $\mathrm{Zn}(\mathrm{acac})_{2}$. The resulting solution intermediate (1) has been reported earlier to be of the type $\mathrm{Zn}_{4} \mathrm{O}\left(\mathrm{CH}_{3} \mathrm{COO}\right)_{6} \cdot{ }^{[38]}$ The experimental spectra of this intermediate are used as a reference in order to verify whether a similar cluster or a polymeric structure also exists in the case of $\mathrm{Zn}(\mathrm{acac})_{2}$ solution intermediate.

Supporting Information (see also the footnote on the first page of this article): Calculated average sizes of $\mathrm{ZnO}$ nanoparticles. Calculated EXAFS parameters. XRD patterns. EDXS for $\mathrm{ZnO}_{-} \mathrm{H}_{2} \mathrm{O}$. Three figures with deconvolutions of the O1s region for $\mathrm{ZnO}_{-}$.

\section{Acknowledgments}

The University of Padua, Italy, the Italian Consorzio Interuniversitario Nazionale per la Scienza e Tecnologia dei Materiali (INSTM) and the National Research Council (CNR) are acknowledged for financial support. A. F. and S. A. gratefully thank the Vigoni Programme for financially supporting the researchers' mobility. TEM analysis has been carried out with partial financial support of the Provincia Autonoma di Trento. The authors would like to thank Prof. Gialanella (University of Trento) for helpful discussion of TEM data and Dr. Roberta Saini (University of Padova) for TGA-DSC measurements. S. A. and H. B. thank the Hamburger Synchrotronstrahlungslabor (HASYLAB) at Deutsches Elektronen-Synchrotron (DESY) Hamburg and Angströmquelle Karlsruhe (ANKA) for providing synchrotron radiation beam time for XAS measurements.

[1] a) H. Morkoç, Ü. Özgür, Zinc Oxide: Materials Preparation, Properties, and Devices, Wiley VCH, Weinheim, 2008; b) Z. L. Wong, Mater. Today 2004, 7, 26-33; c) L. Yichun, T. Yanhong, J. Nanosci. Nanotechnol. 2008, 8, 1101-1109; d) K. Ellmer, A. Klein, Springer Ser. Mater. Sci. 2008, 104, 1-33; e) C. Klingshirn, ChemPhysChem 2007, 8, 782-803; f) C. Klingshirn, R. Hauschild, H. Priller, M. Decker, J. Zeller, H. Kalt, Superlattices Microstruct. 2005, 38, 209-222; g) Z. Fan, J. G. Lu, J. Nanosci. Nanotechnol. 2005, 5, 1561-1573; h) U. Ozgur, Y. Alivov, C. Liu, A. Teke, M. A. Reshchikov, S. Dogan, V. Avrutin, S. J. Cho, H. Morkoc, J. Appl. Phys. 2005, 98, 1-103; i) S. J. Pearton, D. P. Norton, K. Ip, Y. W. Heo, T. Steiner, Prog. Mater. Sci. 2005, 50, 293-340; j) Y. Lu, J. Zhong, Semiconductor Nanostructures for Optoelectronic Applications, Artech House Publishers, Norwood, 2004, p. 187; k) Z. L. Wang, J. Phys.: Condens. Matter 2004, 16, R829-R858; 1) D. C. Look, Mater. Sci. Eng., B 2001, B80, 383-387; m) S. Kwon, T. Hyeon, Acc. Chem. Res. 2008, 41, 1696-1709.

[2] a) C. Bundesmann, R. Schmidt-Grund, M. Schubert, Optical Properties of $\mathrm{ZnO}$ and Related Compounds, in: Transparent Conductive Zinc Oxide (Eds.: K. Ellmer, A. Klein, B. Rech), Springer, Berlin, Springer Series in Materials Science, vol. 104, pp. 79-124; b) J. Muth, A. Osinsky, G. F. Neumark, I. L. Kuskovsky, H. Jiang, Wide Band Gap Light Emitting Materials and Devices, Wiley-VCH, Weinheim, 2007, p. 179; c) A. K. Sood, Y. R. Puri, R. Yash, C. Lao, W. Mai, P. Gao, S. Xu, Z. L. Wang, D. L. Polla, M. B. Soprano, N. K. Dhar, in: Proceedings of SPIE: The International Society for Optical Engineering 2007, 6768, 676803/1-676803/11; d) T. W. Kang, S. U. Yuldashev, G. N. Panin, A. A. Balandin, Handbook of Semiconductor Nanostructures and Nanodevices, 1st ed., American Scientific Publishers, Stevenson Ranch, CA, USA, 2006, vol. 4, p. 159; e) A. B. Djurisic, Y. H. Leung, Small 2006, 2, 944-961; f) R. Bertoncello, M. Bettinelli, M. Casarin, A. Gulino, E. Tondello, A. Vittadini, Inorg. Chem. 1992, 31, 1558-1565; g) T. Andelman, Y. Gong, M. Polking, M. Yin, I. Kuskovsky, G. Neumark, S. O'Brien, J. Phys. Chem. B 2005, 109, 14314.

[3] a) D. C. Look, J. Electron. Mater. 2006, 35, 1299-1305; b) C. Klingshirn, H. Priller, M. Decker, J. Brueckner, H. Kalt, R. Hauchild, J. Zeller, A. Waag, A. Bakin, H. Wehmann, K. Thonke, R. Sauer, R. Kling, F. Reuss, C. Kirchner, Adv. Solid State Phys. 2006, 45, 275-287.

[4] a) A. A. Sokol, S. A. French, S. T. Bromley, C. R. A. Catlow, H. J. J. van Dam, P. Sherwood, Farady Discuss. 2007, 134, 267 282; b) S. Polarz, J. Strunk, V. Ischenko, M. W. E. van den Berg, O. Hinrichsen, M. Muhler, M. Driess, Angew. Chem. Int. Ed. 2006, 45, 2965-2969.

[5] C. Hariharan, Appl. Catal. A 2006, 304, 55-61.

[6] S. Kar, B. N. Pal, S. Chaudhuri, D. Chakravorty, J. Phys. Chem. $B$ 2006, 110, 4605-4611. 
[7] H. Weller, Philos. Trans. R. Soc. London, Ser. A 2003, 361, 229240.

[8] a) K. P. Loh, S. J. Chua, Top. Appl. Phys. 2007, 109, 92-117; b) D. Ehrentraut, H. Sato, Y. Kagamitani, H. Sato, A. Yoshikawa, T. Fukuda, Prog. Cryst. Growth Charact. Mater. 2006, $52,280-335$.

[9] a) L. Spanhel, J. Sol-Gel Sci. Technol. 2006, 39, 7-24; b) L. Spanhel, M. A. Anderson, J. Am. Chem. Soc. 1991, 113, 28262833.

[10] a) M. Niederberger, G. Garnweitner, N. Pinna, G. Neri, Prog. Solid State Chem. 2006, 33, 59-70; b) I. Bilecka, I. Djerdj, M. Niederberger, Chem. Commun. 2008, 886-888; c) J. Buha, I. Djerdj, M. Niederberger, Cryst. Growth Des. 2007, 7, 113-116; d) N. Pinna, G. Garnweitner, M. Antonietti, M. Niederberger, J. Am. Chem. Soc. 2005, 127, 5608-5612; e) G. Clavel, M.-G. Willinger, D. Zitoun, N. Pinna, Adv. Funct. Mater. 2007, 17, 3159; N. Pinna, S. Grancharov, P. Beato, P. Bonville, M. Antonietti, M. Niederberger, Chem. Mater. 2005, 17, 3044-3049.

[11] a) Y. Kashiwaba, T. Abe, S. Onodera, F. Masuoka, A. Nakagawa, H. Endo, I. Niikura, Y. Kashiwaba, J. Cryst. Growth 2007, 298, 477-480; b) C. W. Lin, T. Y. Cheng, L. Chang, J. Y. Juang, Phys. Status Solidi C 2004, 1, c851-c855; c) T. Yasuda, S. Takashi, I. Yusaburo, Phys. Status. Solidi C 2004, 1, b676b679; d) S. Takashi, S. Yusaburo, Phys. Status Solidi B 2004, 241, 676-679; e) J. J. Wu, S. C. Liu, Adv. Mater. 2002, 14, 215218; f) J. Kubota, K. Haga, Y. Kashiwaba, H. Watanabe, B. P. Zhang, Y. Segawa, Appl. Surf. Sci. 2003, 216, 431-435; g) S. C. Liu, J. J. Wu, J. Mater. Chem. 2002, 12, 3125-3129; J. B. Baxter, E. S. Aydil, J. Electrochem. Soc. 2009, 156, H52-H58.

[12] J. J. Wu, S. C. Liu, C. Chien-Ting, K. H. Chen, L. C. Chen, Appl. Phys. Lett. 2002, 81, 1312-1314.

[13] A. Maldonado, M. Olvera, R. Asomoza, S. Tirado-Guerra, $J$. Mater. Sci. 2001, 12, 623-625.

[14] C. Fauteux, R. Longtin, J. Pegna, D. Therriault, Inorg. Chem. 2007, 46, 11036-11047.

[15] Y. Kashiwaba, K. Haga, H. Watanabe, B. P. Zhang, Y. Segawa, K. Wakatsuki, Phys. Status Solidi B 2002, 229, 921-924.

[16] J. F. Liu, Y. Y. Bei, H. P. Wu, D. Shen, J. Z. Gong, X. G. Li, Y. W. Wang, N. P. Jiang, J. Z. Jiang, Mater. Lett. 2007, 61, $2837-2840$

[17] C. Chory, R. Neder, B. Reinhard, V. I. Korsunskiy, F. Niederdraenk, C. Kumpf, E. Umbach, M. Schumm, M. Lentze, J. Geurts, G. Astakhov, W. Ossau, G. Mueller, Phys. Status Solidi C 2007, 4, 3260-32699.

[18] M. Epifani, E. Pellicer, J. Arbiol, J. R. Morante, R. Joan, Chem. Mater. 2009, 21, 862-870; B. K. Woo, W. Chen, A. G. Joly, R. Sammaynaiken, J. Phys. Chem. C 2008, 112, 1429214296.

[19] J. P. Fackler, M. L. Mittleman, H. Weigold, G. M. Barrow, $J$. Phys. Chem 1968, 72, 4631-4636.

[20] Y. Inubushi, R. Takami, M. Iwasaki, H. Tada, S. Ito, J. Colloid Interface Sci. 1998, 200, 220-227; M. Iwasaki, Y. Inubushi, S. Ito, J. Mater. Sci. Lett. 1997, 16, 1503-1505.

[21] M. J. Bennett, F. A. Cotton, R. Eiss, Acta Crystallogr., Sect. B 1968, 24, 904-913.

[22] A. Einstein, Ann. Phys. 1905, 17, 549-555.
[23] a) R. Viswanatha, P. K. Santra, C. Dasgupta, D. D. Sarma, Phys. Rev. Lett. 2007, 98, 255501-255510; b) E. Hosono, S. Fujihara, T. Kimura, H. Imai, J. Sol-Gel Sci. Technol. 2004, 29, 71-79; c) R. Viswanatha, H. Amenitsch, D. D. Sarma, J. Am. Chem. Soc. 2007, 129, 4470-4475; d) E. A. Meulenkamp, J. Phys. Chem. B 1998, 102, 5566-5572; e) D. W. Bahnemann, C. Kormann, M. R. Hoffmann, J. Phys. Chem. 1987, 91, 37893798; f) E. M. Wong, J. J. E. Bonevich, P. C. Searson, J. Phys. Chem. B 1998, 102, 7770-7775; g) M. Iwasaki, Y. Inubushu, S. Ito, J. Mater. Sci. Lett. 1997, 16, 1503-1505.

[24] R. Seshadri, G. N. Subbanna, V. Vijayakrishnan, G. U. Kulkarni, G. Anantakrishna, C. N. R. Rao, J. Phys. Chem. 1995, 99, $5639-5645$.

[25] a) H. D. Dörfler, Grenzflächen und kolloid-disperse SystemePhysik und Chemie, Springer Verlag, Berlin, 2002; b) G. Oskam, Z. Hu, R. L. Penn, N. Pesika, P. C. Searson, Phys. Rev. E 2002, 66, 011403-011407; c) Z. Hu, D. J. Escamilla Ramirez, B. E. Heredia Cervera, G. Oskam, P. C. Searson, Phys. Chem. B 2005, 109, 11209-11211; d) K. J. Hartlieb, C. L. Raston, M. Saunders, Chem. Mater. 2007, 19, 5453-5459.

[26] D. H. Everett, Basic Principles of Colloid Science, RSC Paperbacks, London, 1988.

[27] a) JCPDS 36-1451; b) O. Garcia-Martinez, R. M. Rojas, E. Vila, J. L. Martín de Vidales, Solid State Ionics 1993, 63-65, 442-449.

[28] a) P. Scherrer, Nachrichten der Akademie der Wissenschaften in Göttingen, 1918, 2, 98-101; b) H. P. Klug, L. E. Alexander, $X$ ray Diffraction Procedures for Polycrystalline and Amorphous Materials, Wiley, New York, 1954.

[29] J. L. Lábár, Ultramicroscopy 2005, 103, 237-249.

[30] C. Wöll, Prog. Surf. Sci. 2007, 82, 55-120.

[31] E. P. Parry, J. Catal. 1963, 2, 371; C. Morterra, A. Chiorino, G. Ghiotti, E. Fisicaro, J. Chem. Soc. Faraday Trans. 1982, 78, 2649.

[32] D. Briggs, M. P. Seah, Practical Surface Analysis, Wiley, New York, 1990.

[33] A. Shirley, Phys. Rev. B 1972, 5, 4709-4713.

[34] J. F. Moulder, W. F. Stickle, P. E. Sobol, K. D. Bomben, Handbook of X-ray Photoelectron Spectroscopy, J. Chastain, PerkinElmer Corp., Eden Prairie, MN, 1992.

[35] a) C. D. Wagner, A. V. Naumkin, A. Kraut-Vass, J. W. Allison, C. J. Powell, J. R. Rumble Jr., NIST X-ray Photoelectron Spectroscopy Database, Version 3.5, NIST, Gaithersburg, MD, 2003; b) Z. G. Wang, X. T. Zu, S. Zhu, L. M. Wang, Physica E 2006, 35, 199-202.

[36] P. Kubelka, F. Munk, Zeitschrift für technische Physik 1931, 12, 593; G. Kortum, Reflectance Spectroscopy, Springer, New York, 1969.

[37] a) B. Ravel, M. Newville, J. Synchrotron Radiat. 2005, 12, 537541; b) A. Hübner, D. Stroybusch, H. W. Lerner, M. Bolte, J. Chem. Crystallogr. 2008, 38, 953-957.

[38] V. Briois, C. Giorgetti, E. Dartyge, F. Baudelet, M. S. Tokumoto, S. H. Pulcinelli, C. V. Santilli, J. Sol-Gel Sci. Technol. 2006, $39,25-36$

Received: June 5, 2009

Published Online: October 22, 2009 